\title{
Diet and Sleep Physiology: Public Health and Clinical Implications
}

\author{
Sarah Frank ${ }^{1 \dagger}$, Kelli Gonzalez ${ }^{2 \dagger}$, Lorraine Lee-Ang ${ }^{3 \dagger}$, Marielle C. Young ${ }^{3,4 \dagger}$, Martha Tamez ${ }^{5}$ \\ and Josiemer Mattei ${ }^{5 *}$
}

'Department of Global Health and Population, Harvard T.H. Chan School of Public Health, Boston, MA, United States, ${ }^{2}$ Department of Environmental Health, Harvard T.H. Chan School of Public Health, Boston, MA, United States, ${ }^{3}$ Department of Social and Behavioral Sciences, Harvard T.H Chan School of Public Health, Boston, MA, United States, ${ }^{4}$ Department of Medical Education, Icahn School of Medicine at Mount Sinai, New York, NY, United States, ${ }^{5}$ Department of Nutrition, Harvard T.H. Chan School of Public Health, Boston, MA, United States

OPEN ACCESS

Edited by:

David Gozal,

University of Chicago,

United States

Reviewed by:

Catherine Huggins,

Monash University, Australia

Thirumagal Kanagasabai,

McGill University, Canada

*Correspondence: Josiemer Mattei jmattei@hsph.harvard.edu

tThese authors have contributed equally to this work.

Specialty section: This article was submitted to Sleep and Chronobiology, a section of the journal

Frontiers in Neurology

Received: 17 May 2017

Accepted: 24 July 2017

Published: 11 August 2017

Citation: Frank S, Gonzalez K, Lee-Ang L, Young MC, Tamez M and Mattei J (2017) Diet and Sleep Physiology:

Public Health and Clinical Implications.

Front. Neurol. 8:393. doi: 10.3389/fneur.2017.00393
This mini-review examines the complex relationship between diet and sleep and explores the clinical and public health implications of the current evidence. Dietary quality and intake of specific nutrients can impact regulatory hormonal pathways to alter sleep quantity and quality. Sleep, in turn, affects the intake of total energy, as well as of specific foods and nutrients, through biological and behavioral mechanisms. Initial research in this field focused primarily on the effects of short sleep duration on nutritional quality. However, more recent studies have explored the dynamic relationship between long sleep duration and diet. Current evidence suggests that extremes of sleep duration alter sleep patterns, hormonal levels, and circadian rhythms, which contribute to weight-related outcomes and obesity, and other risk factors for the development of chronic disease such as type 2 diabetes and cardiovascular disease. These patterns may begin as early as childhood and have impacts throughout the life course. Given that non-communicable diseases are among the leading causes of death globally, deeper understanding of the interactions between sleep and nutrition has implications for both public health and clinical practice.

Keywords: diet and sleep, nutrition and sleep, sleep quantity, sleep quality, sleep physiology

\section{INTRODUCTION}

In contrast to other lifestyle risk factors of chronic disease, sleep has not been accorded the same amount of attention in public health or clinical research and practice until recently. There exist complex processes linking sleep duration, quality, and behaviors to both nutrition and risk of chronic disease (Figure 1). Currently, the evidence suggests a bidirectional relationship between sleep quality and duration and diet. These sleep components and their interactions with diet subsequently affect the risk of developing chronic disease. Here, we summarize the main evidence for these complex relationships. We also review the evidence for the effects of diet quality, sleeppromoting foods, and dietary composition on sleep outcomes. We then consider the influence of sleep quality and quantity on risk of chronic disease, such as obesity and weight-related outcomes, type 2 diabetes, and cardiovascular disease (CVD). We extend this discussion by examining the relationships between sleep and diet throughout the life course. Finally, we discuss the clinical and public health implications of this evidence and suggest possible directions for future research. Of note, this mini-review summarizes the literature on human studies, while recognizing that there are data from animal experimental studies that have explored potential mechanisms relating diet and sleep. 


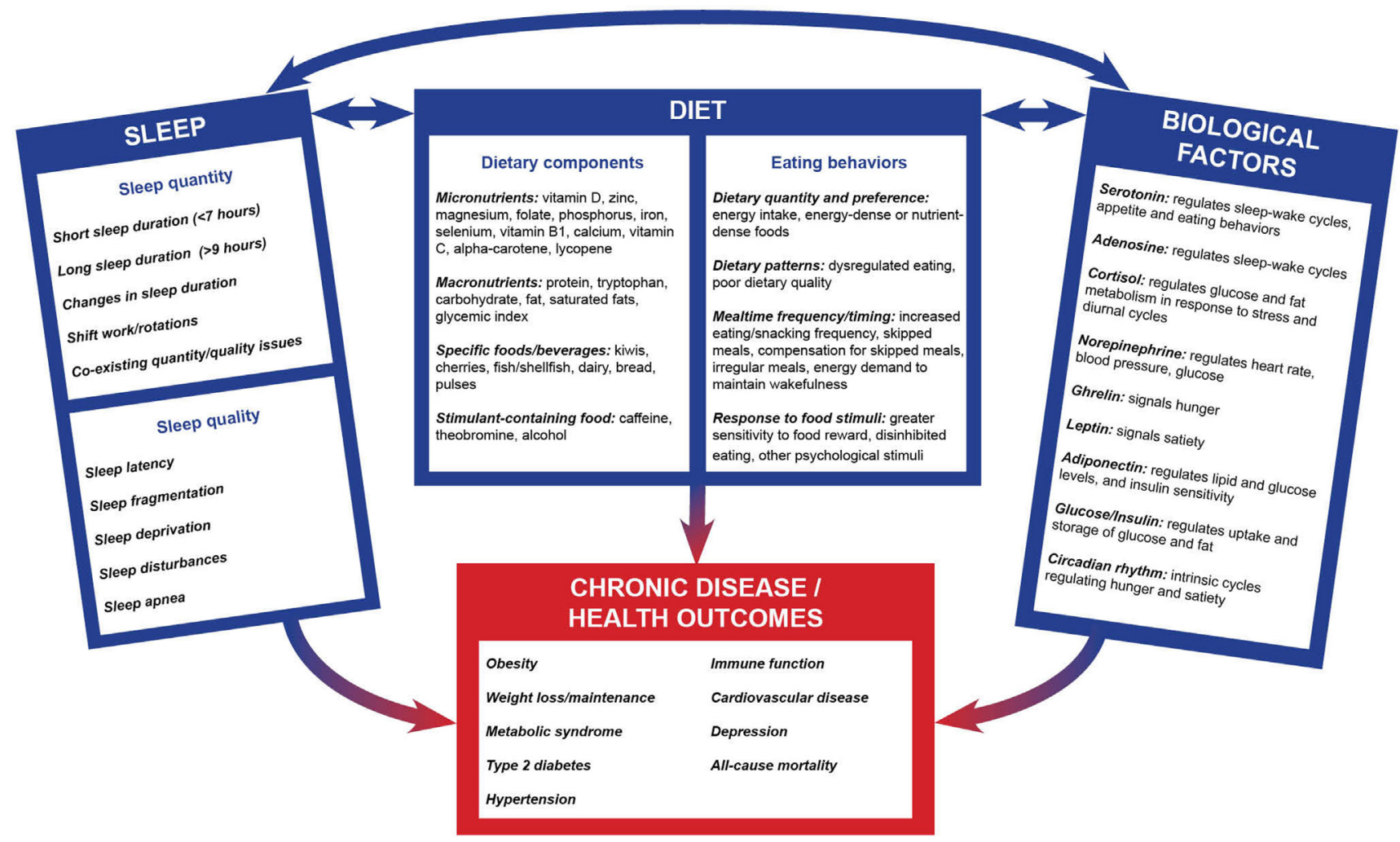

FIGURE 1 | Conceptual framework for the interconnections between dietary factors, sleep, and disease. The complex, bidirectional, relationship between sleep components, dietary composition, behavioral factors, and biological factors are theorized to affect the development of chronic diseases and other health outcomes. Intake of nutrients and foods and dietary behaviors are correlated with components of sleep quality and quantity. Dietary components and eating behaviors are regulated by biological factors, which in turn may impact nutritional status. Similarly, sleep quantity and quality result in biological factors being modulated, and these biological factors control sleep factors in return. Dietary components, sleep components, and biological factors have subsequent independent as well as interactive effects on downstream health outcomes. Notably, this multifaceted interaction is evident early in life and continues throughout the life course.

\section{SCIENTIFIC EVIDENCE}

\section{Diet and Sleep}

Dietary composition, with a focus on specific dietary components, has been shown to influence sleep duration, quality, and behaviors (1-4). We cite studies analyzing the role of macronutrients, micronutrients, and whole foods on sleep (Table 1); most have been small trials or cross-sectional studies conducted in healthy adults. For macronutrients, low fiber, high-saturated fat, and sugar intake were associated with lighter, less restorative sleep, over ad libitum diet, in an inpatient sleep crossover study (5). In another study, a high-carbohydrate/low-fat diet was associated with poorer sleep quality vs. a normal balanced diet or a lowcarbohydrate/high-fat diet (6). Protein and carbohydrate deficiencies have also been associated with shorter sleep duration (4). A study found that consuming high-glycemic index carbohydrate meals approximately $4 \mathrm{~h}$ before bedtime decreased sleep latency, or the time to sleep initiation, which was attributed to an increase in tryptophan after carbohydrate consumption (7). Tryptophan is an amino acid precursor to the sleep-regulating hormone serotonin and is often mentioned as important in the proposed relationships between diet and sleep (8). Furthermore, another study found that evening dietary increases in tryptophan intake improved sleep in adults with sleep disturbances and enhanced alertness in the morning, most likely as a result of improved sleep quality $(9,10)$.

Micronutrients intake have also been suggested to affect sleep patterns. For example, associations have been reported for deficiencies in vitamin B1, folate, phosphorus, magnesium, iron, zinc, and selenium with shorter sleep duration (4), lack of alpha-carotene, selenium, and calcium with difficulty falling asleep, low intake of vitamin $\mathrm{D}$ and lycopene with sleep maintenance, and low intake of calcium and vitamin $\mathrm{C}$ with nonrestorative sleep (11). Short-term trials have shown that nightly intake of melatonin, magnesium, or zinc improved sleep quality in long-term care facility residents with insomnia (12), and use of vitamin D supplement resulted in better outcomes for sleep quality, sleep latency, and sleep duration in adults with a sleep disorder (13). The evidence for zinc is further supported by another randomized, double-blinded, placebo-controlled trial in healthy adults that showed that zinc-rich foods improved sleep onset latency and sleep efficiency over placebo (14). Moreover, optimal magnesium levels, rather than levels above or below the clinically recommended range, have been found in a mice study to be required for normal sleep regulation. The exact mechanisms through which these micronutrients may 
TABLE 1 | Example of studies linking dietary components and sleep outcomes.

\begin{tabular}{|c|c|c|c|c|}
\hline Study design & Participants & Dietary component & Sleep outcome & Reference \\
\hline \multicolumn{5}{|c|}{ Macronutrients or energy intake } \\
\hline Laboratory-based intervention & Young healthy males & $\begin{array}{l}\text { High-carbohydrate/low-fat (vs. low-carbohydrate/ } \\
\text { high-fat or balanced isocaloric diets) }\end{array}$ & Less slow-wave sleep & Phillips et al. (6) \\
\hline Laboratory-based experiment & Young healthy males & $\begin{array}{l}\text { High-glycemic index carbohydrate meals (vs. low } \\
\text { glycemic index) }\end{array}$ & Shortening of sleep onset latency & Afaghi et al. (7) \\
\hline Cross-sectional survey & Adults (general population) & Fat intake & Decreased sleep duration & Shi et al. (41) \\
\hline $\begin{array}{l}\text { Parallel, randomized, } \\
\text { controlled, open label trial }\end{array}$ & $\begin{array}{l}\text { Men with obesity and } \\
\text { moderate to severe } \\
\text { obstructive sleep apnea }\end{array}$ & $\begin{array}{l}\text { Liquid very low energy diet followed by gradual } \\
\text { normal food (vs. usual diet) }\end{array}$ & Improved obstructive sleep apnea & $\begin{array}{l}\text { Johansson } \\
\text { et al. (43) }\end{array}$ \\
\hline Longitudinal cohort & $\begin{array}{l}\text { 3-month-old infants } \\
\text { followed-up until age } 2\end{array}$ & $\begin{array}{l}\text { Higher energy intakes at the evening meal } \\
\text { Carbohydrates (especially from high Gl or high } \\
\text { GL foods) }\end{array}$ & Longer sleep duration & $\begin{array}{l}\text { Diethelm et al. } \\
\text { (63) }\end{array}$ \\
\hline $\begin{array}{l}\text { Randomized, crossover } \\
\text { intervention }\end{array}$ & $\begin{array}{l}\text { Inpatient normal weight } \\
\text { adults }\end{array}$ & $\begin{array}{l}\text { Low fiber, high-saturated fat, and sugar intake vs. } \\
\text { ad libitum }\end{array}$ & $\begin{array}{l}\text { Lighter, less restorative sleep with } \\
\text { more arousals }\end{array}$ & $\begin{array}{l}\text { St-Onge et al. } \\
(1,5)\end{array}$ \\
\hline \multicolumn{5}{|l|}{ Micronutrients } \\
\hline $\begin{array}{l}\text { Double-blind, placebo- } \\
\text { controlled trial }\end{array}$ & Healthy young adults & $\begin{array}{l}\text { Tryptophan-rich diet (vs. tryptophan-low placebo } \\
\text { protein) }\end{array}$ & $\begin{array}{l}\text { Reduced sleepiness and sustained } \\
\text { alertness in the following morning }\end{array}$ & $\begin{array}{l}\text { Markus et al. } \\
\text { (9) }\end{array}$ \\
\hline $\begin{array}{l}\text { Double-blind, placebo- } \\
\text { controlled clinical trial }\end{array}$ & $\begin{array}{l}\text { Older adults with primary } \\
\text { insomnia in a long-term } \\
\text { care facility }\end{array}$ & $\begin{array}{l}\text { Food supplement with melatonin, magnesium, } \\
\text { and zinc (vs. placebo) }\end{array}$ & $\begin{array}{l}\text { Improved sleep quality (getting to } \\
\text { sleep, quality of sleep, alertness } \\
\text { upon awakening) and sleep time }\end{array}$ & $\begin{array}{l}\text { Rondanelli } \\
\text { et al. (12) }\end{array}$ \\
\hline Cross-sectional analysis & Adults (general population) & $\begin{array}{l}\text { Deficiency in vitamin B1, folate, iron, zinc, } \\
\text { phosphorus, magnesium, and selenium }\end{array}$ & Shorter sleep duration & $\begin{array}{l}\text { Grandner et al. } \\
\text { (4) }\end{array}$ \\
\hline Cross-sectional analysis & Adults (general population) & $\begin{array}{l}\text { Deficiency in alpha-carotene, selenium, calcium, } \\
\text { vitamin D, lycopene, and vitamin C }\end{array}$ & $\begin{array}{l}\text { Difficulty falling asleep, sleep } \\
\text { maintenance, or non-restorative } \\
\text { sleep }\end{array}$ & $\begin{array}{l}\text { Grandner et al. } \\
\text { (11) }\end{array}$ \\
\hline Double-blind, clinical trial & Adults with sleep disorders & Vitamin D supplement (vs. placebo) & $\begin{array}{l}\text { Improved sleep quality, reduced } \\
\text { sleep latency, increased sleep } \\
\text { duration, and improved subjective } \\
\text { sleep quality }\end{array}$ & Majid et al. (13) \\
\hline $\begin{array}{l}\text { Randomized, double-blinded, } \\
\text { placebo-controlled parallel } \\
\text { group trial }\end{array}$ & Healthy adults & $\begin{array}{l}\text { Zinc-rich food (vs. zinc-, and astaxanthin-rich } \\
\text { food or placebo supplemented with zinc-enriched } \\
\text { yeast and astaxanthin oil, or placebo) }\end{array}$ & $\begin{array}{l}\text { Decreased time needed to fall } \\
\text { asleep and improved sleep } \\
\text { efficiency }\end{array}$ & Saito et al. (14) \\
\hline
\end{tabular}

\section{Foods}

placebo-controlled, crossover

Randomized, double-blind, Healthy older adults with Tart cherry juice beverage (vs. placebo)

crossover chronic insomnia

Laboratory-based experiment Middle-aged and elderly Jerte Valley cherry cultivars healthy adults

Valley cherry cultivars

\begin{tabular}{lll} 
& healthy adults & \\
\hline Free-living, self-controlled diet & $\begin{array}{l}\text { Adults with self-reported } \\
\text { sleep disturbance }\end{array}$ & Kiwi fruit \\
\hline Randomized, & Inpatient male adults & $\begin{array}{l}\text { Atlantic salmon (vs. alternative meal, i.e., pork, } \\
\text { placebo-controlled }\end{array}$ \\
\hline Cross-sectional analysis & $\begin{array}{l}\text { Middle-aged and older } \\
\text { adults }\end{array}$ & Oily fish consumption
\end{tabular}

Improved sleep efficiency and

Yamamura number of wakening episodes

et al. (21)

Reduction in insomnia severity

Pigeon et al.

(24)

Beneficial effects on sleep time,

total nocturnal activity, assumed

Garrido et al. sleep, and immobility

\begin{tabular}{ll}
$\begin{array}{l}\text { Improved sleep onset, duration, } \\
\text { and efficiency }\end{array}$ & Lin et al. (26) \\
Better daily functioning & $\begin{array}{l}\text { Hansen et al. } \\
(22)\end{array}$ \\
\hline Better sleep quality & $\begin{array}{l}\text { Del Brutto et al. } \\
(23)\end{array}$
\end{tabular}

Eating behaviors

Cross-sectional survey Middle-school children

"Unhealthy eating habits and environments" and "snacking between meals and after supper" (identified by factor analysis)
Shorter sleep and poor sleep quality
Khan et al. (65)

\section{Mixed dietary components}

Cross-sectional analysis
Healthy adult men
Percentage of energy from protein, energy-
adjusted intake of sodium, vitamin D, and vitamin
Longer sleep duration

Komada et al.

(27) 
affect sleep remains unclear (15). Micronutrients have also been proposed as mediators of diet-disease associations; for example, carotenoids and vitamin D mediate associations between sleep duration and waist circumference or systolic blood pressure, and vitamin $\mathrm{C}$ mediates the sleep duration-diastolic blood pressure relationship (16).

Intake of stimulant-containing foods and beverages similarly affects elements of sleep. Caffeine and theobromine are competitive antagonists to adenosine, a hormone that regulates sleep-wake cycles (17). While caffeine and theobromine provide immediate energy after consumption, there are also longer lasting effects consequences that alter sleep patterns for many hours after intake, including prolonged sleep latency, reduced total sleep time, sleep inefficiency, worsened perceived sleep quality, and REM sleep behavior disorder $(18,19)$. In addition, alcohol, which is often regarded as a sedative, has a nuanced impact on sleep. Consumption of alcohol decreases sleep latency and may disrupt sleep later due to its ability to influence levels of serotonin and norepinephrine (20).

There is evidence that particular whole foods affect sleep. For example, milk, fatty fish, cherries, and kiwis have been associated with beneficial effects on sleep outcomes (1, 21-26). The relatively high content of tryptophan found in some of these specific foods may be responsible for these observed associations $(7,8)$. Intake of bread, pulses, and fish and shellfish has been positively correlated with sleep duration in men (27). Finally, there is evidence to suggest that changes in daily dietary composition and eating behaviors can subsequently affect elements of sleep (28).

\section{Sleep and Chronic Disease}

Growing evidence suggests that sleep patterns, such as short $(<7 \mathrm{~h})$ and long $(>9 \mathrm{~h})$ sleep duration, can impact risk of chronic disease (29). Short sleep has received more scrutiny, and it has been associated with an increased risk of obesity, type 2 diabetes, and CVD (29); it also impairs glucose metabolism, which aggravates the risk of type 2 diabetes (30). Researchers hypothesize that short sleep duration may interfere with the body's restorative processes that occur during sleep, leading to biological and behavioral risk factors for chronic disease development (31).

Biologically, sleep influences the circulating levels of the hunger signaling hormones ghrelin and leptin. Ghrelin indicates hunger and leptin signals satiety; sleep deprivation causes high levels of ghrelin and low levels of leptin. Therefore, the hormonal imbalance of ghrelin and leptin may induce overeating behaviors $(30,32)$. Furthermore, adiponectin, a secretory product of adipose tissue that is found in lower levels in the plasma of individuals with obesity, is inversely associated with sleep duration in teenage girls (33). Sleep deprivation also causes greater neuronal activation in response to food stimuli, which results in increased motivation to seek food with high energy intake, particularly energy-dense foods high in fat and sugar (1).

Another pathway by which sleep deprivation and disorders contribute to metabolic dysregulation is through activation of the hypothalamic-pituitary-adrenal (HPA) axis, which deregulates neuroendocrine parameters such as cortisol, leading to downstream increases in glucose and insulin and decreases in adiponectin levels (34). The HPA-axis pathway, along with increased sympathetic nervous system activity and inflammatory responses, has been implicated in the relationship between short sleep duration and increased risk for hypertension, coronary heart disease, recurrent acute coronary syndrome, and heart failure (35).

Circadian disturbances are another possible mechanism linking short sleep behaviors (such as shift work and sleep deprivation) and dietary behaviors and intake (meals irregularity and infrequency) to weight-related outcomes (36). Small laboratory studies conducted with healthy adults have established the presence of intrinsic circadian rhythms regulating hunger, satiety, and food-specific appetite $(37,38)$, as well as increases in energy expenditure with sleep deprivation or decreases with wakefulness and recovery events (39). Moreover, it has been reported that men have higher energy intake during sleep restriction and late-night hours, making them more susceptible to weight gain during sleep loss (40).

As for behavioral mechanisms, both short sleep duration and poor sleep quality are correlated with increased energy intake, poor diet quality, and dysregulated dietary patterns, which can lead to weight gain $(2,3,41)$. Other proposed behaviors include more time and opportunities for eating, psychological distress, greater sensitivity to food reward, disinhibited eating, more energy needed to sustain extended wakefulness, and changes in appetite hormones (2). Indeed, those who experience short sleep duration demonstrate more irregular eating patterns, including more frequent, smaller, and energy-dense foods during nonregular mealtimes (3).

Sleep deficiency may thus promote excess energy intake by affecting both eating behaviors and dietary composition (2). There is an established association between short sleep duration and higher total energy and fat intake (3). For example, individuals sleeping less than $7 \mathrm{~h}$ per night have a significantly higher proportion of total energy intake from fat, compared to those sleeping the recommended 7-9 h per night. In fact, the evidence suggests an inverse dose-response relationship between sleep and fat intake (41).

While the association between sleep and weight gain has been well studied and appears robust (42), the effect on weight loss remains unclear. Randomized clinical trials have suggested that weight loss and weight maintenance through diet and lifestyle interventions can contribute to sleep improvements (43-47), although these have been mostly conducted in patients with preexisting sleep disorders. One clinical trial reported a direct association between sleep duration and successful weight loss (48). However, further research is needed to elucidate the directionality of these associations, and whether sleep improvement could lead to weight loss in the general population.

Finally, there is emerging evidence regarding the association between long sleep duration, usually defined as more than $9 \mathrm{~h}$ of sleep, and chronic disease (49-51). Long sleep duration has been associated with higher risk of CVD, type 2 diabetes, depression, obesity, and chronic kidney disease in trials and observational studies $(29,49-53)$. However, the mechanisms for these relationships are not clear $(49,50)$. There may be unobservable reverse causation bias, as these conditions may 
cause sleep disruptions, such as sleep apnea and sleep fragmentation, that are then associated with long sleep duration. Coexisting poor sleep quality and longer sleep duration have also been shown to be associated with higher cortisol reactivity in adolescents in a cross-sectional study (54) and higher incident coronary heart disease in a cohort of women (55). Moreover, evidence from prospective studies suggests that changes in sleep duration may increase the risk of metabolic syndrome, type 2 diabetes, and CVD mortality as well as of all-cause mortality (56-58). Studies have shown that workers with habitual changes in their shift rotations, and thus in their sleep patterns, have physical inactivity, overweight, sleep deprivation, increased cortisol secretion, and higher inflammation (59-61). Therefore, current evidence suggests that the relationship between sleep duration and risk of chronic disease is J-shaped, such that "extremes of sleep duration" may better predict elevated chronic disease risk (62).

\section{Diet and Sleep throughout the Life Course}

The complex relationship between diet, sleep, and risk factors for chronic disease becomes evident early in life and continues throughout the life course. The impact of dietary composition on sleep patterns has been observed in early childhood. In a cohort of 1- and 2-year-old children, higher energy intake during the evening meal was associated with longer sleep duration (63). Studies of sleep patterns in children also highlight the impact on biological risk factors-particularly the dysregulation of ghrelin and leptin-that contribute to chronic disease risk. A longitudinal study that evaluated sleep duration and leptin found that chronic short sleep duration was associated with lower levels of leptin later in childhood and was exacerbated in girls with greater body adiposity (64). There is also evidence that eating behaviors affect sleep in children. A cross-sectional study found that children who snack in-between meals or after dinner demonstrate decreased sleep duration and quality (65). Furthermore, decreased sleep duration in children has been associated with higher obesity risk (66).

Similar to the pattern observed in young children, adolescents that report short sleep duration have elevated ghrelin and relatively low leptin levels (32). Adolescents are at particularly high risk for short sleep duration and currently report the highest prevalence of insufficient sleep (68.9\%) (67). There are several unique behavioral risk factors that may account for this finding, including increased electronic device use and unhealthy diets (68-72). Nearly one-quarter of adolescents report using an electronic device "constantly," and $72 \%$ report bringing their cellphones into their bedrooms and using them while trying to fall asleep (68). Increased screen time has been associated with poorer sleep quality, unhealthy eating behaviors, and decreased physical activity $(69,70)$. In addition, adolescents with short sleep duration eat significantly fewer servings of fruits and vegetables and have increased odds of fast food consumption, relative to adolescents who sleep for $8 \mathrm{~h}$ per night (71). Similarly, adolescents sleeping fewer than $8 \mathrm{~h}$ per night consumed a higher proportion of energy from fat and a lower proportion of energy from carbohydrates compared with adolescents sleeping more than $8 \mathrm{~h}$ (72). Compounding these risk factors, adolescents are frequently the target audience for marketing of energy-dense, nutrient-poor food, and beverage products (73). The combination of short sleep duration and an obesogenic environment among adolescents may contribute to developing eating behaviors and dietary choices that increase the risk of further sleep disturbances and chronic disease. In fact, sleep deprivation in adolescents has subsequently been associated with a higher risk for obesity, decreased insulin sensitivity, and hypertension $(74,75)$.

Much of the research regarding the relationship between diet and sleep has been conducted in healthy, young or middle-aged adult populations. There is less evidence regarding the relationship between sleep and nutrition in the elderly, or in subgroups with preexisting conditions. The limited research conducted with the elderly echoes that found in younger populations. Among the elderly, poor sleep quality has been associated with obesity, hypertension, metabolic syndrome, and type 2 diabetes (76-78). However, many of these studies are cross-sectional, and issues of reverse causality are especially relevant in elderly populations, who are already at elevated risk of developing these conditions.

\section{IMPLICATIONS FOR PUBLIC HEALTH AND CLINICAL PRACTICE}

According to the National Sleep Foundation, both diet quality and sleep duration are poor and have been declining steadily in the U.S. population $(66,79)$. In $2010,42 \%$ of U.S. adults and more than $50 \%$ of U.S. children reported insufficient sleep (80). Concurrently, lifestyle risk factors that may be influenced by sleep and are protective against chronic disease have been on the decline: the percent of the U.S. population adhering to five healthy lifestyle habits decreased from 15\% in 1988 to $8 \%$ in 2006 (81). The changes in the U.S. reflect global patterns of reported sleep disturbances and shifts toward unhealthier lifestyle behaviors, especially in low-income Asian and African countries (82). These trends highlight the importance of translating the existing scientific evidence focusing on the relationship between sleep patterns and nutrition into messages, programs, and interventions that the public can easily understand and utilize to prevent chronic disease.

Nevertheless, there are few official sleep recommendations available to guide health practitioners and the general population. In the U.S., the National Sleep Foundation has published agespecific, evidence-based recommendations for sleep duration to lower the risk of chronic disease (83). The American Academy of Sleep Medicine has also provided pediatric and adult recommendations for sleep duration $(84,85)$. The 2015 Dietary Guidelines for Americans include recommendations about physical activity and other aspects of a healthy lifestyle; however, they do not include recommendations on the integral relationship between diet and sleep (86). Considering the mounting literature, information on sleep should be incorporated into future iterations of the Dietary Guidelines for Americans to further enhance healthy lifestyle recommendations. Similarly, global agencies and other countries could dedicate more resources to this topic to provide population-wide recommendations on sleep and nutrition. 
In addition, there should be efforts to incorporate sleeprelated content into existing interdisciplinary programs that target nutrition and other relevant aspects of health. Initial work in this area has been promising. For example, in a communitybased intervention focused on wellness, participants experienced improvements in dietary quality, sleep duration, and indicators of obesity (87). An intervention to prevent adverse sleep behaviors among pregnant women demonstrated a protective effect against obesity in the child's first 2 years of life (81). Most encouraging, these improvements have been observed in individuals from a variety of cultural and socioeconomic backgrounds (87-89).

Additional strategies could help improve the approach to sleep and nutrition in the clinical setting. We recommend the following actions: (1) train and educate health-care professionals on the relationship between diet and sleep, particularly those caring for at-risk groups; (2) develop and apply rapid, validated screeners to assess diet composition, eating behaviors, and sleep patterns, to help identify and counsel at-risk patients; and (3) develop new and integrative therapies that account for the critical associations between diet and sleep.

\section{Future Research}

Despite the evidence and public health recommendations presented here, there is still a gap in understanding the complex relationship between sleep, diet, and nutrition, and risk for chronic disease. Much of the evidence to date has been done in cross-sectional studies or small trials, making it difficult to define causal pathways between various dietary components and sleep or to generalize results. More research is needed to understand the mechanisms by which specific nutrients, foods, and eating behaviors impact quality and quantity of sleep. This could be achieved through laboratory studies, larger randomized clinical trials, and longitudinal analyses of diet and sleep outcomes. Similarly, these studies can help identify potential mechanisms that mediate the relationship between sleep, diet, and risk for chronic disease. Future research should seek to strengthen the evidence linking short and long sleep duration and risk of chronic disease. Such research would inform clinical and public health recommendations regarding the specific dietary and sleep behaviors associated with the lowest risk of developing chronic conditions.

At the population level, emerging research has explored the social determinants of sleep in the U.S. A recent study found

\section{REFERENCES}

1. St-Onge M, Mikic A, Pietrolungo CE. Effects of diet on sleep quality. Adv Nutr Int Rev J (2016) 7(5):938-49. doi:10.3945/an.116.012336

2. Chaput JP. Sleep patterns, diet quality and energy balance. Physiol Behav (2014) 134(1):86-91. doi:10.1016/j.physbeh.2013.09.006

3. Dashti HS, Scheer FA, Jacques PF, Lamon-Fava S, Ordovas JM. Short sleep duration and dietary intake: epidemiologic evidence, mechanisms, and health implications. Adv Nutr (2015) 6(6):648-59. doi:10.3945/ an. 115.008623

4. Grandner MA, Jackson N, Gerstner JR, Knutson KL. Dietary nutrients associated with short and long sleep duration. Data from a nationally representative sample. Appetite (2013) 64:71-80. doi:10.1016/j. appet.2013.01.004 that poor sleep quality was directly related to indicators of socioeconomic status and race/ethnicity, with African-American and Hispanic/Latino populations reporting the poorest sleep quality (90). Addressing the many barriers to optimal sleep and nutrition in underserved and minority populations is crucial to improving health on a population level. Research is needed to identify feasible, culturally appropriate interventions that target sleep- and nutrition-related health gaps. Finally, given the emergence of sleep disturbances as a global epidemic (82), research in other countries, especially low-income countries, is needed. Such research could be used to guide future sleep recommendations about sleep practices and nutrition in high-risk populations across the globe.

\section{AUTHOR CONTRIBUTIONS}

SF, KG, LL-A, and MY conceptualized the topic, researched and analyzed the background literature, and wrote the manuscript, including interpretations and conclusions. JM analyzed the content to prepare the table and portions of the figure and manuscript. MT and JM provided substantial scholarly guidance on the conception of the topic, manuscript draft and interpretation, and revised the manuscript critically for intellectual content. All the authors approved the final version of the manuscript, ensured the accuracy and integrity of the work, and agreed to be accountable for all aspects of the work.

\section{ACKNOWLEDGMENTS}

The authors appreciate the comments from our colleagues from the 2016 Principles of Nutrition course at Harvard TH Chan School of Public Health. The authors recognize Brett O. Otis, Amina Gueye, and Xiaolu Amelia Zhang Gross for creating the graphic design of the figure.

\section{FUNDING}

KG was support by a Harvard ERC/NIOSH training grant (grant number T42 OH008416). MT was supported by the National Council of Science and Technology (CONACyT, Mexico). JM was supported by a NIH-NHLBI Mentored Career Development Award to Promote Faculty Diversity in Biomedical Research (grant number K01-HL120951).

5. St-Onge M, Roberts A, Shechter A, Choudhury AR. Fiber and saturated fat are associated with sleep arousals and slow wave sleep. J Clin Sleep Med (2016) 12(1):19-24. doi:10.5664/jcsm.5384

6. Phillips F, Chen CN, Crisp AH, Koval J, McGuinness B, Kalucy RS, et al. Isocaloric diet changes and electroencephalographic sleep. Lancet (1975) 2(7938):723-5. doi:10.1016/S0140-6736(75)90718-7

7. Afaghi A, O'Connor H, Chow CM. High-glycemic-index carbohydrate meals shorten sleep onset. Am J Clin Nutr (2007) 85(2):426-30.

8. Peuhkuri K, Sihvola N, Korpela R. Diet promotes sleep duration and quality. Nutr Res (2012) 32(5):309-19. doi:10.1016/j.nutres.2012.03.009

9. Markus C, Jonkman L, Lammers J, Deutz N, Messer M, Rigtering N. Evening intake of $\alpha$-lactalbumin increases plasma tryptophan availability and improves morning alertness and brain measures of attention. Am J Clin Nutr (2005) 81(5):1026-33. 
10. Silber B, Schmitt J. Effects of tryptophan loading on human cognition, mood, and sleep. Neurosci Biobehav Rev (2010) 34(3):387-407. doi:10.1016/j. neubiorev.2009.08.005

11. Grandner M, Jackson N, Gerstner J, Knutson K. Sleep symptoms associated with intake of specific dietary nutrients. J Sleep Res (2014) 23(1):22-34. doi:10.1111/jsr.12084

12. Rondanelli M, Opizzi A, Monteferrario F, Antoniello N, Manni R, Klersy C. The effect of melatonin, magnesium, and zinc on primary insomnia in long-term care facility residents in Italy: a double-blind, placebo-controlled clinical trial. J Am Geriatr Soc (2011) 59(1):82-90. doi:10.1111/j.1532-5415.2010.03232.x

13. Majid MS, Ahmad HS, Bizhan H, Mohammad Hosein HZ, Mohammad A. The effect of vitamin D supplement on the score and quality of sleep in 20-50 year-old people with sleep disorders compared with control group. Nutr Neurosci (2017):1-9. doi:10.1080/1028415X.2017.1317395

14. Saito H, Cherasse Y, Suzuki R, Mitarai M, Ueda F, Urade Y. Zinc-rich oysters as well as zinc-yeast- and astaxanthin-enriched food improved sleep efficiency and sleep onset in a randomized controlled trial of healthy individuals. Mol Nutr Food Res (2017) 61(5). doi:10.1002/mnfr.201600882

15. Chollet D, Franken P, Raffin Y, Henrotte JG, Widmer J, Malafosse A, et al. Magnesium involvement in sleep: genetic and nutritional models. Behav Genet (2001) 31(5):413-25. doi:10.1023/A:1012790321071

16. Kanagasabai T, Ardern CI. Contribution of inflammation, oxidative stress, and antioxidants to the relationship between sleep duration and cardiometabolic health. Sleep (2015) 38(12):1905-12. doi:10.5665/sleep.5238

17. Ribeiro JA, Sebastiao AM. Caffeine and adenosine. J Alzheimer Dis (2010) 20(1):3-15. doi:10.3233/JAD-2010-1379

18. Vorona RD, Ware J. Exacerbation of REM sleep behavior disorder by chocolate ingestion: a case report. Sleep Med (2002) 3(4):365-7. doi:10.1016/ S1389-9457(02)00008-4

19. Clark I, Landolt H. Coffee, caffeine, and sleep: a systematic review of epidemiological studies and randomized controlled trials. Sleep Med Rev (2017) 31:70-8. doi:10.1016/j.smrv.2016.01.006

20. Roehrs T, Roth T. Sleep, sleepiness, sleep disorders and alcohol use and abuse. Sleep Med Rev (2001) 5(4):287-97. doi:10.1053/smrv.2001.0162

21. Yamamura S, Morishima H, Kumano-go T, Suganuma N, Matsumoto H, Adachi H, et al. The effect of Lactobacillus helveticus fermented milk on sleep and health perception in elderly subjects. Eur J Clin Nutr (2009) 63(1):100-5. doi:10.1038/sj.ejcn.1602898

22. Hansen AL, Dahl L, Olson G, Thornton D, Graff IE, Frøyland L, et al. Fish consumption, sleep, daily functioning, and heart rate variability. J Clin Sleep Med (2014) 10(5):567-75. doi:10.5664/jcsm.3714

23. Del Brutto OH, Mera RM, Ha JE, Gillman J, Zambrano M, Castillo PR. Dietary fish intake and sleep quality: a population-based study. Sleep Med (2016) 17:126-8. doi:10.1016/j.sleep.2015.09.021

24. Pigeon WR, Carr M, Gorman C, Perlis ML. Effects of a tart cherry juice beverage on the sleep of older adults with insomnia: a pilot study. J Med Food (2010) 13(3):579-83. doi:10.1089/jmf.2009.0096

25. Garrido M, Paredes SD, Cubero J, Lozano M, Toribio-Delgado AF, Muñoz JL, et al. Jerte valley cherry-enriched diets improve nocturnal rest and increase 6-sulfatoxymelatonin and total antioxidant capacity in the urine of middle-aged and elderly humans. J Gerontol A Biol Sci Med Sci (2010) 65(9):909-14. doi:10.1093/gerona/glq099

26. Lin HH, Tsai PS, Fang SC, Liu JF. Effect of kiwifruit consumption on sleep quality in adults with sleep problems. Asia Pac J Clin Nutr (2011) 20(2):169-74.

27. Komada Y, Narisawa H, Ueda F, Saito H, Sakaguchi H, Mitarai M, et al. Relationship between self-reported dietary nutrient intake and selfreported sleep duration among Japanese adults. Nutrients (2017) 9(2):E134. doi:10.3390/nu9020134

28. St-Onge MP, Shechter A. Sleep disturbances, body fat distribution, food intake and/or energy expenditure: pathophysiological aspects. Horm Mol Biol Clin Investig (2014) 17(1):29-37. doi:10.1515/hmbci-2013-0066

29. American Heart Association. Sleep duration and quality: impact on lifestyle behaviors and cardiometabolic health: a scientific statement from the American Heart Association. Circulation (2016) 134(18):367-86. doi:10.1161/ CIR.0000000000000444

30. Arora T, Choudhury S, Taheri S. The relationships among sleep, nutrition, and obesity. Curr Sleep Med Rep (2015) 1(4):218-25. doi:10.1007/ s40675-015-0030-z
31. Broussard J, Brady M. The impact of sleep disturbances on adipocyte function and lipid metabolism. Best Pract Res Clin Endocrinol Metab (2010) 24(5):763-73. doi:10.1016/j.beem.2010.08.007

32. Taheri S, Lin L, Austin D, Young T, Mignot E. Short sleep duration is associated with reduced leptin, elevated ghrelin, and increased body mass index. PLoS Med (2004) 1(3):e62. doi:10.1371/journal.pmed.0010062

33. Al-Disi D, Al-Daghri N, Khanam L, Al-Othman A, Al-Saif M, Sabico S, et al. Subjective sleep duration and quality influence diet composition and circulating adipocytokines and ghrelin levels in teen-age girls. Endocr J (2010) 57(10):915-23. doi:10.1507/endocrj.K10E-145

34. Hirotsu C, Tufik S, Andersen M. Interactions between sleep, stress, and metabolism: from physiological to pathological conditions. Sleep Sci (2015) 8(3):143-52. doi:10.1016/j.slsci.2015.09.002

35. Javaheri S, Redline S. Insomnia and risk of cardiovascular disease. Chest (2017). doi:10.1016/j.chest.2017.01.026

36. Ekmekcioglu C, Touitou Y. Chronobiological aspects of food intake and metabolism and their relevance on energy balance and weight regulation. Obes Rev (2011) 12(1):14-25. doi:10.1111/j.1467-789X.2010.00716.x

37. Sargent C, Zhou X, Matthews RW, Darwent D, Roach GD. Daily rhythms of hunger and satiety in healthy men during one week of sleep restriction and circadian misalignment. Int J Environ Res Public Health (2016) 13(2):170. doi:10.3390/ijerph13020170

38. Scheer FA, Morris CJ, Shea SA. The internal circadian clock increases hunger and appetite in the evening independent of food intake and other behaviors. Obesity (2013) 21(3):421-3. doi:10.1002/oby.20351

39. Jung CM, Melanson EL, Frydendall EJ, Perreault L, Eckel RH, Wright KP. Energy expenditure during sleep, sleep deprivation and sleep following sleep deprivation in adult humans. J Physiol (2011) 589(Pt 1):235-44. doi:10.1113/ jphysiol.2010.197517

40. Spaeth AM, Dinges DF, Goel N. Sex and race differences in caloric intake during sleep restriction in healthy adults. Am J Clin Nutr (2014) 100(2):559-66. doi:10.3945/ajcn.114.086579

41. Shi Z, McEvoy M, Luu J, Attia J. Dietary fat and sleep duration in Chinese men and women. Int J Obes (2008) 32(12):1835-40. doi:10.1038/ ijo.2008.191

42. Patel SR, Hu FB. Short sleep duration and weight gain: a systematic review. Obesity (2008) 16:643-53. doi:10.1038/oby.2007.118

43. Johansson K, Neovius M, Lagerros YT, Harlid R, Rossner S, Granath F, et al. Effect of a very low energy diet on moderate and severe obstructive sleep apnoea in obese men: a randomised controlled trial. Br J Med (2009) 339:b4609. doi:10.1136/bmj.b4609

44. Foster GD, Borradaile KE, Sanders MH, Millman R, Zammit G, Newman AB, et al. A randomized study on the effect of weight loss on obstructive sleep apnea among obese patients with type 2 diabetes: the sleep AHEAD study. Arch Intern Med (2009) 169(17):1619-26. doi:10.1001/ archinternmed.2009.266

45. Nerfeldt P, Nilsson BY, Udden J, Rossner S, Fribergl D. Weight reduction improves nocturnal respiration in obese sleep apnoea patients-A randomized controlled pilot study. Obes Res Clin Pract (2008) 2(2):119-24. doi:10.1016/j. orcp.2008.08.001

46. Tuomilehto HP, Seppa JM, Partinen MM, Peltonen M, Gylling H, Tuomilehto JO, et al. Lifestyle intervention with weight reduction: first-line treatment in mild obstructive sleep apnea. Am J Respir Crit Care Med (2009) 179(4):320-7. doi:10.1164/rccm.200805-669OC

47. Araghi MH, Chen YF, Jagielski A, Choudhury S, Banerjee D, Hussain S, et al. Effectiveness of lifestyle interventions on obstructive sleep apnea (OSA): systematic review and meta-analysis. Sleep (2013) 36(10):1553-62, 1562A-1562E. doi:10.5665/sleep.3056

48. Elder CR, Gullion CM, Funk KL, Debar LL, Lindberg NM, Stevens VJ. Impact of sleep, screen time, depression, and stress on weight change in the intensive weight loss phase of the LIFE study. Int J Obes (2012) 36(1):86-92. doi:10.1038/ ijo.2011.60

49. Furuncuoğlu Y, Emet S, Kose M, Sertkaya AC, Aras S. Is long sleep duration a new risk factor for obesity? Int J Clin Exp Med (2016) 9(8):16741-6.

50. Tsai T-C, Wu J-S, Yang Y-C, Huang Y-H, Lu F-H, Chang C-J. Long sleep duration associated with a higher risk of increased arterial stiffness in males. Sleep (2014) 37(8):1315-20. doi:10.5665/sleep.3920

51. Buxton OM, Marcelli E. Short and long sleep are positively associated with obesity, diabetes, hypertension, and cardiovascular disease among adults 
in the United States. Soc Sci Med (2010) 71(5):1027-36. doi:10.1016/j. socscimed.2010.05.041

52. Sabanayagam C, Shankar A. Sleep duration and cardiovascular disease: results from the National Health Interview Survey. Sleep (2010) 33(8): 1037-42. doi:10.1093/sleep/33.8.1037

53. Choi H, Kim HC, Lee JY, Lee JM, Choi DP, Suh I. Sleep duration and chronic kidney disease: the Korean genome and epidemiology study (KoGES)Kangwha study. Korean J Intern Med (2017) 32(2):323-34. doi:10.3904/ kjim. 2015.400

54. Mrug S, Tyson A, Turan B, Granger DA. Sleep problems predict cortisol reactivity to stress in urban adolescents. Physiol Behav (2016) 155:95-101. doi:10.1016/j.physbeh.2015.12.003

55. Sands-Lincoln M, Loucks EB, Lu B, Carskadon MA, Sharkey K, Stefanick ML, et al. Sleep duration, insomnia, and coronary heart disease among postmenopausal women in the Women's Health Initiative. J Womens Health (Larchmt) (2013) 22(6):477-86. doi:10.1089/jwh.2012.3918

56. Song Q, Liu X, Zhou W, Wang X, Wu S. Changes in sleep duration and risk of metabolic syndrome: the Kailuan prospective study. Sci Rep (2016) 6:36861. doi:10.1038/srep36861

57. Song Q, Liu X, Zhou W, Wang X, Wu S. Short-term changes in sleep duration and risk of type 2 diabetes: Kailuan prospective study. Medicine (2016) 95(45):e5363. doi:10.1097/MD.0000000000005363

58. Ferrie JE, Shipley MJ, Cappuccio FP, Brunner E, Miller MA, Kumari M, et al. A prospective study of change in sleep duration: associations with mortality in the Whitehall II cohort. Sleep (2007) 30(12):1659-66. doi:10.1093/ sleep/30.12.1659

59. Sonati JG, De Martino MM, Vilarta R, da Silva Maciel É, Sonati RJ, Paduan PC. Quality of life, sleep, and health of air traffic controllers with rapid counterclockwise shift rotation. Workplace Health Saf (2016) 64(8):377-84. doi:10.1177/2165079916634710

60. Niu SF, Chung MH, Chen CH, Hegney D, O'Brien A, Chou KR. The effect of shift rotation on employee cortisol profile, sleep quality, fatigue, and attention level: a systematic review. J Nurs Res (2011) 19(1):68-81. doi:10.1097/ JNR.0b013e31820c1879

61. Viitasalo K, Puttonen S, Kuosma E, Lindström J, Härmä M. Shift rotation and age - interactions with sleep-wakefulness and inflammation. Ergonomics (2015) 58(1):65-74. doi:10.1080/00140139.2014.958573

62. Grandner M. Addressing sleep disturbances: an opportunity to prevent cardiometabolic diseases? Int Rev Psychiatry (2014) 26(2):155-76. doi:10.31 09/09540261.2014.911148

63. Diethelm K, Remer T, Jilani H, Kunz C, Buyken AE. Associations between the macronutrient composition of the evening meal and average daily sleep duration in early childhood. Clin Nutr (2011) 30(5):640-6. doi:10.1016/j. clnu.2011.05.004

64. Boeke C, Storfer-Isser A, Redline S, Taveras E. Childhood sleep duration and quality in relation to leptin concentration in two cohort studies. Sleep (2014) 37(3):613-20. doi:10.5665/sleep.3510

65. Khan M, Faught EL, Chu YL, Ekwaru JP, Storey KE, Veugelers PJ. Is it nutrients, food items, diet quality or eating behaviours that are responsible for the association of children's diet with sleep? J Sleep Res (2017) 26(4):468-76. doi:10.1111/jsr.12466

66. Iglowstein I, Jenni OG, Molinari L, Largo RH. Sleep duration from infancy to adolescence: reference values and generational trends. Pediatrics (2003) 111(2):302-7. doi:10.1542/peds.111.2.302

67. Eaton D, McKnight-Eily L, Lowry R, Perry G, Presley-Cantrell L, Croft J. Prevalence of insufficient, borderline, and optimal hours of sleep among high school students - United States, 2007. J Adolesc Health (2010) 46(4):399-401. doi:10.1016/j.jadohealth.2009.10.011

68. Richter R. Go to Bed: Social and School Pressures Prompt Many Stressed Teens to Forsake Sleep. (2015). Available from: http://stanmed.stanford.edu/2015fall/ go-to-bed.html

69. Christofaro DGD, De Andrade SM, Mesas AE, Fernandes RA, Farias J, Cazuza J. Higher screen time is associated with overweight, poor dietary habits and physical inactivity in Brazilian adolescents, mainly among girls. Eur J Sport Sci (2016) 16(4):498-506. doi:10.1080/17461391.2015.1068868

70. Pyper E, Harrington D, Manson H. The impact of different types of parental support behaviours on child physical activity, healthy eating, and screen time: a cross-sectional study. BMC Public Health (2016) 16(1):568. doi:10.1186/ s12889-016-3245-0
71. Kruger AK, Reither EN, Peppard PE, Krueger PM, Hale L. Do sleep-deprived adolescents make less-healthy food choices? Br J Nutr (2014) 111(10): 1898-904. doi:10.1017/S0007114514000130

72. Weiss A, Xu F, Storfer-Isser A, Thomas A, Ievers-Landis CE, Redline S. The association of sleep duration with adolescents' fat and carbohydrate consumption. Sleep (2010) 33(9):1201-9. doi:10.1093/sleep/33.9.1201

73. American Academy of Pediatrics Council on Communications and Media. Children, adolescents, obesity, and the media. Pediatrics (2011) 128(1):201-8. doi:10.1542/peds.2011-1066

74. Garaulet M, Ortega FB, Ruiz JR, Rey-López JP, Béghin L, Manios Y, et al. Short sleep duration is associated with increased obesity markers in European adolescents: effect of physical activity and dietary habits. The HELENA study. Int J Obes (2011) 35:1308-17. doi:10.1038/ijo.2011.149

75. Javaheri S, Storfer-Isser A, Rosen CL, Redline S. Association of short and long sleep durations with insulin sensitivity in adolescents. J Pediatr (2011) 158(4):617-23. doi:10.1016/j.jpeds.2010.09.080

76. López-García E, Faubel R, León-Muñoz L, Zuluaga MC, Banegas JR, Fernando Rodríguez-Artalejo F. Sleep duration, general and abdominal obesity, and weight change among the older adult population of Spain. Am J Clin Nutr (2008) 87(2):310-6.

77. Akbaraly TN, Jaussent I, Besset A, Bertrand M, Barberger-Gateau P, Ritchie K, et al. Sleep complaints and metabolic syndrome in an elderly population: the three-city study. Am J Geriatr Psychiatry (2015) 23(8):818-28. doi:10.1016/j. jagp.2014.10.001

78. Chiang JL, Kirkman MS, Laffel LMB, Peters AL. Type 1 diabetes through the life span: a position statement of the American Diabetes Association. Diabetes Care (2014) 37(7):2034-54. doi:10.2337/dc14-1140

79. National Sleep Foundation. 2014 Sleep Health Index. (2014). Available from: https://sleepfoundation.org/sites/default/files/2014\%20Sleep\%20Health\%20 Index-FINAL_0.PDF

80. National Sleep Foundation. Sleep in America Poll. (2011). Available from: https://sleepfoundation.org/sites/default/files/sleepinamericapoll/SIAP_ 2011_Summary_of_Findings.pdf

81. King D, Mainous A, Carnemolla M, Everett C. Adherence to healthy lifestyle habits in US adults, 1988-2006. Am J Med (2009) 122(6):528-34. doi:10.1016/j. amjmed.2008.11.013

82. Stranges S, Tigbe W, Gómez-Olivé F, Thorogood M, Kandala N. Sleep problems: an emerging global epidemic? Findings from the INDEPTH WHO-SAGE study among more than 40,000 older adults from 8 countries across Africa and Asia. Sleep (2012) 35(8):1173-81. doi:10.5665/ sleep. 2012

83. Hirshkowitz M, Whiton K, Albert SM, Alessi C, Oliviero B, DonCarlos L, et al. National Sleep Foundation's sleep time duration recommendations: methodology and results summary. Sleep Health (2015) 1(1):40-3. doi:10.1016/j. sleh.2014.12.010

84. Paruthi S, Brooks LJ, D’Ambrosio C, Hall WA, Kotagal S, Lloyd RM, et al. Recommended amount of sleep for pediatric populations: a consensus statement of the American Academy of Sleep Medicine. J Clin Sleep Med (2016) 12(6):785-6. doi:10.5664/jcsm.5866

85. Watson NF, Badr MS, Belenky G, Bliwise DL, Buxton OM, Buysse D, et al. Recommended amount of sleep for a healthy adult: a joint consensus statement of the American Academy of Sleep Medicine and Sleep Research Society. Sleep (2015) 38(6):843-4. doi:10.5664/jcsm.4758

86. United States Departments of Agriculture (USDA) \& Health and Human Services (HHS). The Dietary Guidelines for Americans 2015-2020. (2015). Available from: https:/health.gov/dietaryguidelines/2015/guidelines/

87. Tomayko E, Prince R, Cronin K, Parker T, Kim K, Grant V, et al. Healthy children, strong families 2: a randomized controlled trial of a healthy lifestyle intervention for American Indian families designed using community-based approaches. Clin Trials (2017) 14(2):152-61. doi:10.1177/1740774516685699

88. Taylor B, Gray A, Galland B, Heath A, Lawrence J, Sayers R, et al. Targeting sleep, food, and activity in infants for obesity prevention: an RCT. Pediatrics (2017) 139(3):e20162037. doi:10.1542/peds.2016-2037

89. Mantziki K, Vassilopoulos A, Radulian G, Borys J, du Plessis H, Gregório M, et al. Promoting health equity in European children: design and methodology of the prospective EPHE (epode for the promotion of health equity) evaluation study. BMC Public Health (2014) 14(1):303. doi:10.1186/1471-2458-14-303 
90. Patel N, Gradner M, Xie D, Branas C, Gooneratne N. "Sleep disparity" in the population: poor sleep quality is strongly associated with poverty and ethnicity. BMC J Public Health (2010) 10:475. doi:10.1186/1471-2458-10-475

Conflict of Interest Statement: The authors declare that the research was conducted in the absence of any commercial or financial relationships that could be construed as a potential conflict of interest.
Copyright (c) 2017 Frank, Gonzalez, Lee-Ang, Young, Tamez and Mattei. This is an open-access article distributed under the terms of the Creative Commons Attribution License (CC BY). The use, distribution or reproduction in other forums is permitted, provided the original author(s) or licensor are credited and that the original publication in this journal is cited, in accordance with accepted academic practice. No use, distribution or reproduction is permitted which does not comply with these terms. 